\title{
CHARACTERIZING 2-D TOPOGRAPHIC MAPPINGS OF ROADS
}

\author{
JOHN B. FERRIS ${ }^{*}$ AND JOSHUA V. KERN ${ }^{\dagger}$ \\ * Virginia Tech, IALR \\ $\dagger$ Virginia Tech, IALR \\ Danville, VA 24540, USA Danville, VA 24540, USA \\ jbferris@vt.edu
}

Load data representing severe customer usage is needed throughout a chassis development program; the majority of these chassis loads originate with the excitation from the road. These chassis loads are increasingly derived from vehicle simulations, however simulating a vehicle traversing long roads is impractical and a method to produce short roads with given characteristics must be developed. The first step is to consider the road to be a realization of an underlying stochastic process. There are many methods currently available to characterize roads when they are assumed to be homogeneous (see [1], for example). The issue of nonstationarity that arises when a vehicle traverses a homogenous road at a varying speed has also been discussed $[2,3]$. Recent work shows that rough roads that are of interest for durability predictions are not homogeneous, however [4].

This work is focused on the characterization of rough roads for durability predictions. The objective of this work is to determine the correlation between road profile measurement points and to determine if an interval of influence exists. That is, this work establishes the interval of influence for typical rough highways in the United States. This interval can then be used in subsequent stochastic models of the road topology. For example, this modeling could be in the form of an ARMA model or a Markov model. The primary tools for the development of this interval are the variogram and the partial autocorrelations; other concepts are also described. The use of this interval is then discussed in terms of the implications to stochastic modeling and further characterization of road profiles that have either homogeneous or heterogeneous topological properties.

\section{References}

[1] H.E.M. Hunt, "Stochastic Modelling of Vehicles for Calculation of Ground Vibration", Proceedings of the 11th International Association of Vehicle System Dynamics Symposium, Supplement to Vehicle System Dynamics, 18, August 1989, Kingston, Ontario, Canada.

[2] R.C. Redfield, and D.C. Karnopp, "Roadway Elevation Profile Generation for Vehicle Simulation", Vehicle System Dynamics, 17, 267-280, 1988.

[3] J.K. Hammond and R.F. Harrison, "Nonstationary Response of Vehicles on Rough Ground - A State Space Approach", J. Dynamics Systems, Measurement, and Control, 103, 245-50, 1981.

[4] V. Rouillard, M. Sek, and B. Bruscella, "Classification of Road Surface Profiles", J. of Transportation Engineering, ASCE, 127-3, 247-53, 2001.

Keywords: Topographic, Mapping, Road 